\title{
How occupational therapists teach older patients to use bathing and dressing devices in rehabilitation.
}

\author{
Ruth Levine Schemm \\ Thomas Jefferson University \\ Laura N. Gitlin \\ Thomas Jefferson University
}

Follow this and additional works at: https://jdc.jefferson.edu/otfp

Part of the Occupational Therapy Commons

Let us know how access to this document benefits you

\section{Recommended Citation}

Schemm, Ruth Levine and Gitlin, Laura N., "How occupational therapists teach older patients to use bathing and dressing devices in rehabilitation." (1998). Department of Occupational Therapy Faculty Papers. Paper 37.

https://jdc.jefferson.edu/otfp/37

This Article is brought to you for free and open access by the Jefferson Digital Commons. The Jefferson Digital Commons is a service of Thomas Jefferson University's Center for Teaching and Learning (CTL). The Commons is a showcase for Jefferson books and journals, peer-reviewed scholarly publications, unique historical collections from the University archives, and teaching tools. The Jefferson Digital Commons allows researchers and interested readers anywhere in the world to learn about and keep up to date with Jefferson scholarship. This article has been accepted for inclusion in Department of Occupational Therapy Faculty Papers by an authorized administrator of the Jefferson Digital Commons. For more information, please contact: JeffersonDigitalCommons@jefferson.edu. 


\section{How Occupational Therapists Teach Older Patients To Use Bathing and Dressing Devices in Rehabilitation}

\author{
Ruth L. Schemm, Laura N. Gitlin
}

Key Words: patient education - rehabilitation, geriatric $\bullet$ self care

Ruch L. Schemm, EdD, OTR/L, FAOTA, is Assistant Dean of Healch Sciences, and Professor and Chair, Department of Occupational Therapy, Philadelphia College of Pharmacy and Science, 600 Souch 43rd Street, Philadelphia, Pennsylvania $19104-4495$.

Laura N. Gitlin, PhD, is Professor, Department of Occupational Therapy, and Director, Community and Homecare Research Division, College of Health Professions, Thomas Jefferson Universicy, Philadelphia, Pennsylvania.

This article was accepted for publication November 12, 1997.
Objective. This article describes the methods occupational therapists use to teach bathing and dressing device use to older patients in rehabilitation programs. The relationship of three patient characteristics to five aspects of assistive device instruction was examined.

Method. The study sample included 86 patients and 19 occupational therapists who provided the assistive device training. Patients were 55 years of age or older and in rehabilitation for an orthopedic deficit, cerebrovascular accident, or lower limb amputation. Therapists recorded information on teaching methods, perceptions of patient knowledge, and expectations for future device use after each treatment session.

Results. Patients received an average of three dressing and two bathing devices for home use. Therapists devoted an average of two and a half sessions $(10 \mathrm{~min}$ average duration) to teach dressing device use and an average of one session ( 9 min average duration) to teach bathing device use. Teaching occurred mostly in the clinic setting through oral instruction and demonstration. At discharge, patients who evaluated devices positively and were evaluated as having a positive affect were perceived by the therapists as "having greater knowledge of device use." More time was spent teaching those patients with lower Functional Independence Measure scores, less positive evaluations of devices, and lower affect scores. Family caregivers were involved in one or more dressing sessions for $26 \%$ of patients and one or more bathing sessions for $36 \%$ of patients.

Conclusion. Assistive device training in rehabilitation centers consists largely of simulated sessions in the occupational therapy clinic, and patients in the study described the instruction they received as "satisfactory." More research is needed to study the long-term effectiveness of assistive device training after patients return home.

A ssistive technology is an important component of rehabilitation care and is viewed as a key strategy to enhance an older person's ability to resume independent living at home. Occupational therapy practitioners become involved in assistive technology in two ways: They work with patients to encourage them to select, try, and use a number of assistive devices, including a wide range of reasonably priced, low technology items, such as dressing sticks, adaptive shoe laces, reachers, or built-up eating utensils, and they instruct patients and family members on how to use these devices. Given the increased number of older patients who need devices, demands on family members and caregivers, and public and administrative scrutiny of costs, therapists need information on the most effective training approaches for assistive device use. Various authors have addressed how 
to select assistive devices for different impairment groups, how to assess patient needs (Cook \& Hussey, 1995; Levine \& Gitlin, 1993; Mann \& Lane, 1991; Smith, 1995), and the rate of use and abandonment of devices by patients (Bynum \& Rogers, 1987; Geiger, 1990; Gitlin, Schemm, Landsberg, \& Burgh, 1996; Mann, Hurren, \& Tomita, 1995; Neville-Jan, Piersol, Kielhofner, \& Davis, 1993; Rogers \& Holm, 1992), but few have described the methods therapists use to teach patients how to use assistive devices. This article describes how therapists in rehabilitation centers teach older patients to use assistive devices.

\section{Background and Importance}

Prior to the onset of an illness, a patient may not have needed or used any type of device to perform self-care activities. Use of assistive devices, defined as "any item, piece of equipment, or product system, whether acquired commercially, off-the-shelf, modified or customized, that is used to increase, maintain or improve functional capabilities of individuals with disabilities" (Technology-Related Assistance for Individuals With Disabilities Act of 1988 [Public Law 100-407] cited in Cook \& Hussey, 1995, p. 5), can promote adaptation to functional loss (Reilly, 1974; Rogers, 1983; Spuhler, 1965; Tobias, 1966; Washburn, 1960; Zemke \& Horger, 1995). Older adults with chronic conditions are known to use devices in their homes (Gitlin, 1995; Mann, Karuza, Hurren, \& Tomita, 1993). Rate of elders' use of devices after hospital discharge has been reported to range from $35 \%$ to $87 \%$, depending on the type of device and length of time rhat the person has been impaired (Forbes, Hayward, \& Agwani, 1993; Mann et al., 1995).

Mobility, bathing, and dressing devices are the three categories of adaptive equipment that are most commonly issued by therapists in rehabiliration centers (Gitlin et al., 1996; Mann, Hurren, Tomita, \& Charvat, 1996). In a study of a heterogeneous population of 30 hospitalized patients, Finlayson and Havixbeck (1992) found that an average of three devices were given in four teaching sessions. Instruction for each device lasted an average of 11 min, and patients reported satisfaction with the instruction offered. Gitlin and Burgh (1995) identified three factors that influenced therapists' decisions about equipment prescriptions: (a) the parient's medical condition, pathology, and etiology (i.e., functional status, level of impairment); (b) factors that were unique to the patient (i.e., personal goals, motivacion, previous roles); and (c) living arrangemenrs after discharge (i.e., caregiver network, living alone or in a group, living near stores). Other studies identified the characteristics that may influence the process of learning to use a device, such as the patient's beliefs and values (Gitlin et al., 1996; Gitlin, Luborsky, \&
Schemm, in press; Levine, 1984; Luborsky, 1993; Peloquin, 1988), learning ability (Neistadt, 1996), or conflicts with the therapists' values and goals (Becker, 1993; Hesse, Campion, \& Karamouz, 1984; Kaufman, 1981; Levine, 1984; Radomski, 1995).

Adequacy of instruction is another factor that influences adaptive device use. Learning by doing means that the patient uses adaptive devices during treatment sessions, and this experience may provide opportunities to integrate the new tools into daily life habits. Unfortunately, not all patients receive adequate instruction. Neville-Jan et al. (1993) used 50 returned surveys of patients selected from prosthetic records over a 3 -month period of time and found that $15 \%$ of the 92 devices issued to surveyed patients during hospitalization were never used at home, and $21 \%$ were used only for a brief period and then use was discontinued. Reasons for nonuse included poor fit, lack of knowledge about device use, device use not convenient, need diminished, or installation not completed. In other studies, patients identified a lack of knowledge of device use and inappropriate or inadequate instruction as reasons for underuse (Gitlin, 1995; Gitlin \& Levine, 1992; Gitlin, Levine, \& Geiger, 1993; Phillips \& Zhao, 1993). Other factors such as fatigue, pain, discomfort, sense of personal loss, and curtailed funcrion may distract the patient from learning to use an adaprive device (Gitlin er al., in press).

Preparation, interaction, cues, repetition, support, and rewards are part of effective therapeutic teaching, which involves more than a brief demonstration. Effective therapeutic teaching stimulates the learner's desire to learn. Adulr learning specialists have developed five principles for enriching the learning process, and these could be applied to teaching the use of adaptive devices to older persons. First is the basic principle that adults can and do want to learn new skills, regardless of age, and older learners can draw on past experiences when learning new ideas and skills (Caffarella, 1994; Picariello, 1986). Second, older learners are pragmatic and can be motivared by internal and external factors (Caffarella, 1994; Knowles, 1980). Third, a newly developed need often creates the "teachable moment" (Havighurst, 1972), which is when the degree of motivation to learn new behaviors that meet task demands is highest (Long, 1983). Effective teachers address "who the learner is, what he or she cares about, and how he or she perceives and knows" (Wlodkowski \& Ginsberg, 1995, p. 112). Fourth, time is important to learning. The teacher must schedule enough time to present ideas clearly (Picariello, 1986). Fifth, use a concrete rather than a conceptual orientation, use closing remarks to summarize the session, and encourage questions (Picariello, 1986; Neistadt, 1996).

The current study was conducted to describe the 
teaching methods therapists use with older adults in rehabilitation programs to instruct in bathing and dressing device use. Factors of interest were instruction methods, time devored to teaching, location of teaching, inclusion of others, and therapists' perceptions of patient knowledge of use of bathing and dressing devices. It also examined the relationship between patient characteristics (i.e., functional status, psychological well-being, device perceptions) and instructional methods and compared effectiveness of instruction method for patients who had a cerebrovascular accident (CVA) with patients who had an orthopedic condition.

\section{Method}

\section{Sample Selection}

The data reported here were collected as part of a larger study examining elderly persons' postdischarge use of assistive devices issued during their stay in a rehabilitation program. Other findings emanating from this larger study are reported elsewhere (Gitlin et al., 1996; Gitlin et al., in press). Subject recruitment for the larger study resulted in enrollment of 250 patients from two Philadelphia-area rehabilitation hospitals who met the following criteria: (a) 55 years of age or older; (b) hospitalized with a primary condition of CVA, orthopedic deficit, or lower limb amputation; (c) cognitively intact; and (d) discharged to their own home or that of a family member with one or more assistive devices.

A total of 1,885 assistive devices had been issued to the 250 patients. The most frequently issued devices were for mobility ( $94 \%$ of the sample received 1-6 items) followed by bathing ( $84 \%$ received at least 1 item) and dressing devices $(76 \%$ received $1-5$ items). The data reported here were derived from those patients who received both bathing and dressing devices $(N=86)$.

Nineteen occupational therapists documented the rype of device training they offered to these 86 parients (an average of 5 patients per therapist). The occupational therapists had an average of 3 to 12 years of experience.

\section{Patient Self-Report Measures}

Four self-report instruments were administered during a patient interview, which occurred within 3 days before discharge. The self-report measures have been described elsewhere (Gitlin et al., 1996) and are only briefly discussed here.

Measure of satisfaction with device training. Patients were asked to rate the extent to which they were satisfied with device instruction on a five-point scale ( 1 = very dissatisfied, $5=$ very satisfied) and to rate the adequacy of instruction time on a three-point scale $(3=$ adequate, $1=$ not adequate). This measure was developed specifically for the study.

Measure of expectation to use devices. Patients were asked to rate anticipared frequency of use of each issued device when they returned home on a five-point response set $(1=$ never, $5=$ always $)$. Expectations to use dressing and bathing devices were scored separately to calculate an average score for each category. This measure was developed specifically for the study.

Evaluations of devices. To measure positive and negative perceptions of assistive devices, 10 items were developed by the investigators on the basis of previous qualitative research and Bruno's (1993) 36-item Reinforcement Scale. Three items measured positive perceptions (e.g., "devices make me feel independent") and seven measured negative perceptions (e.g., "device use disrupts my life," "takes too long to use device"). The extent to which the patient agreed with each statement was rated on a fivepoint scale $(1=$ not at all, $5=$ extremely $)$. Two indexes were then derived by summing the scores within each domain, positive evaluation of devices, and negative evaluation of devices. Cronbach's alpha was .57 for the positive device index for this study group and .64 for the negative device index.

Psychological well-being. The 10-item Bradburn (1969) Affect-Balance Scale was used to measure psychological well-being. The patient was asked to rate the extent to which he or she experienced 10 affective states $(1=$ not at all, $5=$ extremely). Two subindexes were derived, one reflecting positive affect (Cronbach's alpha $=.71$ ) and the other negative affect (Cronbach's alpha $=.61$ ).

\section{Therapist Documentation}

For each patient, his or her occupational therapist documented specific information about bathing and dressing training and device use at the conclusion of each instructional session on a form designed for this study. Included was the amount of time and number of sessions devoted to teaching; primary site of instruction (i.e., patient room, dining room, bathroom, clinic); involvement of others (i.e., family member, nurse, physical therapist, other patients); method of instruction (i.e., oral, written, demonstration, group); perception of adequacy of patient knowledge of device use ( 4 = good, $1=$ poor $)$; and prediction of the extent to which the patient would use the device at home ( $5=$ always, $1=$ never $)$.

Before data collection, the therapists were trained by the investigative team on how to complete the documentation forms and were provided a set of written directions and coding rules as supplements. A member of the research ream was available to resolve questions emerging in the documentation process, and the on-site occupational therapy supervisor examined each completed form for missing data. 


\section{Functional Independence Measure}

The Functional Independence Measure (FIM) (Granger \& Hamilton, 1992) rates the severity of disability, or burden of care of rehabilitation patients, for 18 items on a seven-point scale $(7$ = complete independence, $1=$ total assistance). FIM scores were collected from the patients' medical charts by a member of the research team. Scores were obtained for all 18 items except two: bladder and bowel management. Two subindexes, one for motor function (which included 11 of the 13 items) and one for social and cognitive function (which included all 5 items), were created by summing item scores.

\section{Data Analysis}

Descriptive statistics were used to describe the characteristics of instruction, and $t$ tests for independent samples were used to determine differences between patients with orthopedic deficits and patients with CVA. Because there were too few patients with a lower limb amputation $(n=$ 6), they were excluded from comparative analyses. Pearson product-moment correlations were used to examine the relationships between characteristics of instruction and patient self-report factors.

\section{Results}

\section{Patient Characteristics}

The majority of patients were Caucasian, women, lived with another, and had been hospitalized for an orthopedic deficit (see Table 1). All patients, regardless of diagnosis, expressed high satisfaction with the device use training they received during their rehabilitation stay $(M=4.88 \pm$ $.45)$ and, for the most part, expressed that time spent in training had been adequate $(M=2.89 \pm .31)$. On average, patients reported positive evaluations of devices and expected to use the bathing $(M=3.92 \pm .76)$ and dressing $(M=3.76 \pm .68)$ devices at home "frequently." Patients with orthopedic deficits and patients with CVA were similar with regard to device evaluations, expectation to use a device at home, and psychological well-being. However, as anticipated, patients with orthopedic deficits had higher motor function scores $(M=67.2 \pm 5.5)$ than did patients with CVA $(M=61.9 \pm 8.7, t=-3.25, p<.01)$ and higher social cognition scores $(M=34.43 \pm 1.4)$ than did patients with CVA $(M=32.44 \pm 3.2, t=-3.64, p<.01)$.

\section{Number and Type of Assistive Devices}

Each patient received, on average, 10 assistive devices for home use, including those for mobility and seating. With regard to bathing devices, 143 devices were prescribed for this sample $(N=86)$ for an average of 2 per patient. These included long-handled sponges $(n=71)$, fexible shower
Table 1

Patient Characteristics

\begin{tabular}{|c|c|c|c|}
\hline Variable & $n(\%)$ & $M(S D)$ & Acrual Range \\
\hline \multicolumn{4}{|l|}{ Background information } \\
\hline Age (years) & & $72.4 \quad(8.63)$ & $56-92$ \\
\hline Education (years) & & $10.55(3.13)$ & $4-18$ \\
\hline \multicolumn{4}{|l|}{ Living arrangemen $\mathrm{r}^{\mathrm{a}}$} \\
\hline Alone & $38(44)$ & & \\
\hline Wirh orher & $46(54)$ & & \\
\hline \multicolumn{4}{|l|}{ Race $^{\mathrm{a}}$} \\
\hline Caucasian & $46(54)$ & & \\
\hline African-American & $38(44)$ & & \\
\hline \multicolumn{4}{|l|}{ Gender } \\
\hline Male & $21(24)$ & & \\
\hline Female & $65(76)$ & & \\
\hline \multicolumn{4}{|l|}{ Medical and funcrional scarus } \\
\hline \multicolumn{4}{|l|}{ Diagnosis } \\
\hline Cerebrovascular accident & $39(45)$ & & \\
\hline Orthopedic deficir & $43(50)$ & & \\
\hline Lower limb ampuration & $4 \quad(5)$ & & \\
\hline Number of secondary diagnoses & & $3.55(1.77)$ & $0-8$ \\
\hline Moror funcrion & & $64.71(7.48)$ & $13-91$ \\
\hline Cognitive function & & $33.54(2.55)$ & $5-35$ \\
\hline Number of issued devices & & $9.71(3.40)$ & $2-17$ \\
\hline \multicolumn{4}{|l|}{ Psychological well-being } \\
\hline Posicive affect & & $14.09(4.36)$ & $5-25$ \\
\hline Negative affect & & $21.53(3.40)$ & $5-25$ \\
\hline Positive device evaluation & & $9.43(3.00)$ & $3-15$ \\
\hline Negarive device evaluarion & & $30.57(4.08)$ & $5-25$ \\
\hline
\end{tabular}

Note. $N=86$.

$\mathrm{a}_{n<86}$ due to missing informarion.

hoses $(n=40)$, diverter valves $(n=27)$, wash mitts ( $n=$ $4)$, and a tub chair $(n=1)$. With regard to dressing devices, 233 were prescribed for this sample for an average of 3 devices per patient. These included shoe horns $(n=$ 64), reachers $(n=59)$, dressing sticks $(n=40)$, stocking aids $(n=31)$, elastic laces $(n=28)$, and other miscellaneous items $(n=11)$.

In general, patients with CVA received a greater number of devices $(M=10.8 \pm 3.8)$ than did patients with orthopedic deficits $(M=8.9 \pm 2.7, t=2.61, p<.01)$, specifically more bathing devices $(M=2.8 \pm 1.2)$ than did parients with orthopedic deficits $(M=2.19 \pm 1.3, t=$ $2.23, p<.05)$. Patients with orthopedic deficits were issued a slightly greater number of dressing devices $(M=$ $2.9 \pm 1.4)$ than were patients with CVA $(M=2.3 \pm 1.3, t$ $=-2.04, p<.05)$.

\section{Characteristics of Training}

Bathing. Therapists devoted an average of one session to instruct in bathing devices, with each session averaging 9 min (see Table 2). On average, therapists perceived that training time was adequate. They rarely involved other patients or health professionals, such as physical therapists or nurses, during training, and only $36 \%$ of patients had a family member present during a bathing instructional session. With regard to instruction methods, a combination of approaches were used in any one session. A therapist may have used more than one type of method and changed location during part of the session. Oral instruc- 
Table 2

Training Characteristics in Bathing and Dressing Devices

\begin{tabular}{lcr}
\hline Characteristic & $\begin{array}{c}\text { Bathing } \\
M(S D)\end{array}$ & \multicolumn{1}{c}{$\begin{array}{c}\text { Dressing } \\
M(S D)\end{array}$} \\
\hline Number of issued devices & $1.66(0.83)$ & $2.72(1.17)$ \\
Sessions per device & $1.37(0.66)$ & $2.54(1.41)$ \\
Minures each session & $8.68(6.81)$ & $10.16(4.88)$ \\
Therapist perception of adequacy of time & $2.70(0.47)$ & $2.90(0.24)$ \\
Therapist perception of patient knowledge of use & $3.95(0.85)$ & $4.20(0.72)$ \\
Therapist expectarion of patient's home use & $3.92(0.76)$ & $3.76(0.68)$ \\
\hline
\end{tabular}

tions were used with $99 \%$ of the patients, demonstration with $88 \%$, and written instructions with $25 \%$. One patient was trained to use a barhing device in a group with other parients. Instruction in bathing device use occurred in the clinic for $88 \%$ of patients, in the patient's room for $22 \%$, and in the bathroom for $12 \%$. On average, therapists reported that they perceived that patients had adequate knowledge of how to use the device and expected that the device would be used in the home with frequency.

Dressing. Therapists devoted an average of two and one-half sessions to instruct patients in dressing devices, with each session averaging $10 \mathrm{~min}$ (see Table 2). As in bathing instrucrion, therapists rarely involved other patients or health professionals in training sessions, and only $24 \%$ of patients had a family member present for one or more dressing instructional sessions. With regard to instruction methods, a combination of approaches were used in any one session. Oral instruction was used with $98 \%$ of the patients, demonstration with $96 \%$, and written instructions with only $5 \%$. Only one patient was trained in a group context. Instruction in dressing device use occurred in the clinic for $86 \%$ of patients, in the patient's room for $62 \%$, and in the bathroom for $6 \%$. As with bathing, on average, therapists perceived that patients had obtained adequate knowledge as to how to use the device and expected that the device would be used in the home with frequency. There were no differences in the length of time spent in training in the use of bathing or dressing devices for patients with CVA or orthopedic deficits.

\section{Relationship of Instruction to Patient Factors}

There was little variation in the variables of instruction that involved inclusion of other health professionals and the method and place of instruction. Therefore, these variables were not considered in the analysis of the relationship between patient factors and other aspects of instruction (i.e., time spent, therapist perception of patient knowledge and use, involvement of a family member). Pearson product-moment correlation coefficients were calculated to examine the relationship between characteristics of instruction and patient factors. For bathing, although the time spent in training was not significantly associated with patient factors, patients with lower scores on the FIM motor subscale received a greater number of training sessions, $r=-.28, p<.01$ (see Table 3). Furthermore, therapists perceived that patients with greater positive affect would use devices with more frequency in the home, $r=.23, p<.05$, and that patients with higher motor, $r=.24, p<.05$, and cognitive function, $r=.33, p<$ .01 , and greater positive affect had greater knowledge of device use, $r=.28, p<.01$. Family involvement in instructional sessions appeared to be associated with patients who had lower cognitive function scores, $r=-.22, p<.01$; greater negative perceptions of devices, $r=-.38, p<.001$; and lower positive evaluations of devices, $r=-.29, p<$ .001 .

A similar pattern emerged for dressing. A greater number of teaching sessions was associated with lower motor, $r=-.32, p<.01$, and cognitive, $r=-.37, p<.001$, funcrion scores; lower positive device evaluations, $r=$ $-.35, p<.001$; and lower positive psychological affect, $r=$ $-.24, p<.05$ (see Table 4). However, the average amount of time spent per session was not related to any of these patient factors. Therapist expectations of parient use of dressing devices in the home was higher for parients with positive affect, $r=.32 ; p<.01$, and therapist rating of a patient's knowledge of device use was greater for those with higher motor function scores, $r=.22, p<.05$; positive device evaluation scores, $r=.28, p<.01$; and positive affect scores, $r=.42, p<.001$. Family involvement was greater for patients with lower negative device evaluations, $r=-23, p<.05$.

\section{Discussion}

Results from this study confirm previous findings, namely that older patients were positive abour assistive device use and were satisfied with occupational therapists' assistive device training (Bynum \& Rogers, 1987; Finlayson \& Havixbeck, 1992). Additionally, we found that the instructional methods used by the occupational therapists in this study were largely oral and included some demonstration. Few patients were given written materials during instruction of assistive device use, which means that many parients returned home with little information on device care, safery precautions, and what to do if the device needed repair or replacement.

We also found that the majority of education and training sessions were located in the occupational therapy clinic or in the patient's room suggesting that most instruction sessions simulated rather than replicated the patient's real-life situation. Shor of conducting sessions in the patient's home, inclusion of family members and caregivers in the training session at the rehabilitation facility may bridge the gap between institution and home. These sessions may be scheduled during evenings and weekends when family members are more likely to be available. We also recommend that these teaching methods be augment- 
Table 3

Pearson Product-Moment Correlation Coefficients of Instructional and Patient Factors for Bathing Devices

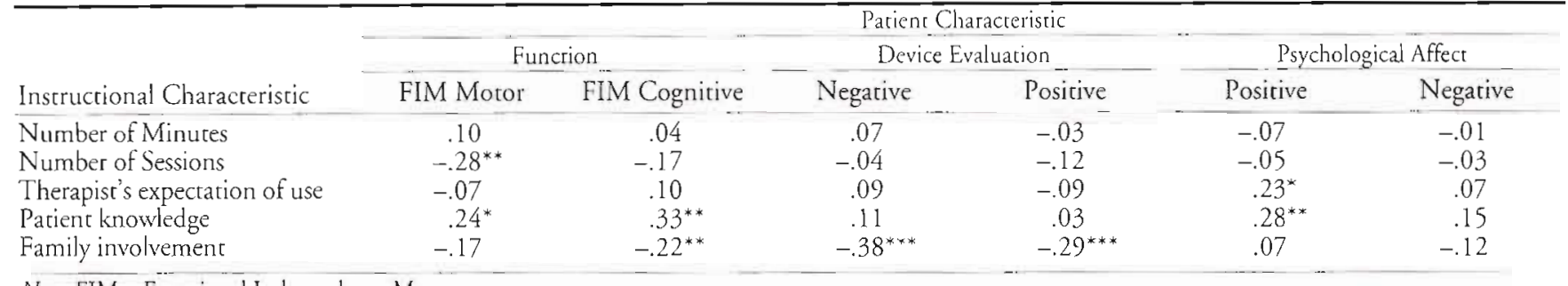

Note. $\overline{\mathrm{FTM}}=$ Functional Independence Measure.

${ }^{*} p<.05 .{ }^{* *} p<.01 .{ }^{* * *} p<.001$

ed with not only easy-to-understand written instructions, but also by videotaped demonstrations, which can be replayed over and over at home. Diagrams and pictures can further reinforce ideas that were presented to the patient. Equipment installation and safety features should be discussed with the patient, described to family members and caregivers and reinforced in written or videotaped materials. Effective device use instruction can minimize nonuse, increase frequency of use, and avoid installation and safety problems (Bynum \& Rogers, 1987; Neistadt, 1996).

The parients in this study received an average of two bathing or three dressing devices, which may be considerable for new users. Both therapists and patients in our study rated the time devoted to instruction in this number of devices as adequate, but future studies may determine whether patients were able to effectively use assistive devices upon return home. Another factor that may influence device use at home is the rearrangement and modification of long-standing personal self-care routines (Gitlin et al., 1993; Levine, 1984; Radomski, 1995; Smith, 1995). Before their hospitalization, the patients in this study had no need for the prescribed devices; they were essentially first-time users. These patients had to learn to use bathing and dressing devices to compensate for losses in funcrional performance while simultaneously having to adapt to their new impairment. Therapists evaluating whether a patient can perform a task with an assistive device might also consider the associated emotional and cultural factors that influence whether the patient will be able and willing to integrate the device into their home dressing or bathing routine.

\section{Limitations}

These findings need to be interpreted in light of several study limitations. First, the reliability of the recordings and time estimates of therapists were difficult to discern. Although therapists were trained and monitored in the use of an instructional tracking form, interrater reliability was not established for the form because of limited time and resources. Second, the average length of stay for patients in this study was 21 days. This has since been reduced to 8 to 14 days. These changes may influence the amount of rime therapists devote to patient education and, therefore, the number of opportunities for patients to try the devices under supervision.

\section{Conclusion}

The findings add to our understanding of how occupational therapists instruct older patients in bathing and dressing device use in rehabilitation. Each patient, who received an average of two bathing and three dressing devices, expressed satisfaction with the device use training they received during rehabilitation. The average time of 9 min for bathing demonstration (average $=$ one session) and $10 \mathrm{~min}$ for dressing demonstration (average $=21 / 2$ sessions) were adequate. Few patients received written materials to reinforce the demonstration(s), and patients returned home with limited information on device use, safery precaurions, and what to do if the device needed replacement or repair.

\section{Acknowledgment}

This research was supported by a grant from the Department of Edu-

Table 4

Pearson Product-Moment Correlation Coefficients of Instructional and Patient Factors for Dressing Devices

\begin{tabular}{|c|c|c|c|c|c|c|}
\hline \multirow[b]{3}{*}{ Instructional Characteristic } & \multicolumn{6}{|c|}{ Patient Characreristic } \\
\hline & \multicolumn{2}{|c|}{ Function } & \multicolumn{2}{|c|}{ Device Evaluncion } & \multicolumn{2}{|c|}{ Psychological Affect } \\
\hline & FIM Motor & FIM Cognitive & Negative & Posicive & Positive & Negative \\
\hline Number of Minutes & .09 & -.04 & .01 & .01 & -.18 & .08 \\
\hline Number of Sessions & $-.32^{* *}$ & $-.37^{x * x}$ & -.13 & $-.35^{* * *}$ & $-.24^{*}$ & -.02 \\
\hline Therapist's expectacion of use & .08 & .07 & .05 & .19 & $.32^{* *}$ & .19 \\
\hline Patient knowledge & $.22^{*}$ & $.23^{\star}$ & -.08 & $28^{* *}$ & $.42^{k * *}$ & .09 \\
\hline Family involvement & -.12 & .01 & $-.23^{*}$ & -.16 & -.01 & -.06 \\
\hline
\end{tabular}

Note. FIM = Funcrional Independence Measure.

${ }^{*} p<.05 .{ }^{* x} p<.01 .{ }^{* * * *} p<.001$. 
cation, National Institure on Disability and Rehabilitarion Research (Grant No. H133G00160).

\section{References}

Becker, G. (1993). Continuity after a stroke: Implications of life-course distuption in old age. Gerontologist, 33, 148-158.

Bradburn, N. M. (1969). The structure of psychological well being. Chicago: Aldine.

Bruno, R. (1993). The reinforcement motivation survey. Hackensack, NJ: Harvesr Press.

Bynum, H., \& Rogers, J. C. (1987). The use and effectiveness of assistive devices possessed by patients seen in home care. Occupational Therapy Joumal of Research, 3, 181-191.

Caffarella, R. S. (1994). Planning programs for adult learners: $A$ practical guide for educators, trainers, and staff developers. San Francisco: Jossey-Bass.

Cook, A. M., \& Hussey, S. M. (1995). Assistive technologies: Principles and practice. St. Louis, MO: Mosby.

Finlayson, M., \& Havixbeck, K. (1992). A post-discharge study on the use of assiscive devices. Canadian Journal of Occupational Therapy, 59, 201-207.

Forbes, W. F., Hayward, L. M., \& Agwani, N. (1993). Factors associated with self-reported use and non-use of assistive devices among impaired elderly residing in the communicy. Canadian Joumal of Public Health, 84(1), 53-57.

Geiger, C. M. (1990). The utilization of assistive devices by parients discharged from acute rehabilitation. Physical and Occupational Therapy in Geriatrics, $9(1), 3-25$.

Gitlin, L. N. (1995, Spring). Why older people accept or reject assistive rechnology. Generations, 41-46.

Gitlin, L. N., \& Burgh, D. (1995). Issuing assistive devices to older patients in rehabilitarion: An exploratory study. American Journal of Occupational Therapy, 49, 994-1000.

Gitlin, L. N., \& Levine, R. E. (1992). Prescribing adaptive devices to the elderly: Principles for treatment in the home. International Journal of Technology and Aging, 5(1), 107-120.

Gitlin, L. N., Levine, R. E., \& Geiger, C. M. (1993). Adaptive device use in the home by older adulss with mixed disabilities. Archives of Physical Medicine and Rehabilitation, 74, 149-152.

Gitlin, L. N., Luborsky, M., \& Schemm, R. L. (in press). Emerging concerns of assistive device use by older stroke pacients in rehabilitation. Gerontologist.

Gitlin, L. N., Schemm, R. L., Landsberg, L., \& Burgh, D. (1996). Factors predicting assistive device use in the home by older persons following rehabilitation. Joumal of Aging and Health, 8, 554 575.

Granger, C. V., \& Hamilton, B. B. (1992). The Uniform Data System for Medical Rehabilitarion report of first admissions for 1990. American Joumal of Physical Medicine and Rehabilitation, 71(4), 108113.

Havighurst, R. J. (1972). Developmental tasks and education. New York: McKay.

Hesse, K. A., Campion, E. W., \& Karamouz, N. (1984). Attitudinal stumbling blocks to geriatric rehabilitation. Journal of the American Geriatrics Society, 32, 747-750.

Kaufman, S. (1981). Cultural components of identity on old age: A case study. Ethos, 2, 51-87.

Knowles, M. S. (1980). The modern practice of adult education. New York: Cambridge University Press.

Levine, R. E. (1984). The cultural aspects of home care delivery. American Joumal of Occupational Therapy, 38, 734-738.
Levine, R. E., \& Gitlin, L. N. (1993). A model to promote activity competence in elders. American Journal of Occupational Therapy, 47, 147-153.

Long, H. B. (1983). Adult learning: Research and practice. New York: Cambridge.

Luborsky, M. (1993). Sociocultural factors shaping technology usage: Fulfilling the promise. Technology and Disability, 2(1), 71-78.

Mann, W. C., Hurren, D., \& Tomita, M. (1995). Assistive devices used by home-based elderly persons with arthritis. American Journal of Occupational Therapy, 49, 810-820.

Mann, W. C., Hurren, D., Tomita, M., \& Charvat, B. (1996). Use of assistive devices for bathing by elderly who are nor institutionalized. Occupational Therapy Journal of Research, 1, 261-286.

Mann, W. C., Karuza, J., Hurren, M. D., \& Tomita, M. (1993). Needs of home-based older persons for assistive devices. Technology and Disability, 2(1), 1-1 1.

Mann, W. C., \& Lane, J. (1991). Assistive technology for persons with disabilities: The role of occupational therapy. Rockville, MD: American Occuparional. Therapy Association.

Neistadt, M. E. (1996). An information processing approach to functional skills training with older adults. Physical and Occupational Therapy in Geriatrics, 14(1), 19-25.

Neville-Jan, A., Piersol, C. V., Kielhofner, G., \& Davis, K. (1993). Adaptive equipment: A study of utilization after hospital discharge. Occupational Therapy in Health Care, 8(4), 3-18.

Peloquin, S. M. (1988). Linking purpose to procedure during interactions with patients. American Journal of Occupational Therapy, 42, 775-781.

Phillips, B., \& Zhao, H. (1993). Predictors of assistive technology abandonment. Assistive Technology, 5(1), 36-45.

Picariello, G. (1986). A guide for teaching elders. Geriatric Nursing-American Journal of Care for the Aging, 7(1), 38-39.

Radomski, M. V. (1995). Narionally Speaking-There is more to life than putting on your pants. American Journal of Occupational Therapy, 49, 487-490.

Reilly, M. (1974). An explanation of play. In M. Reilly (Ed.), Play as exploratory learning (pp. 117-149). Beverly Hills, CA: Sage.

Rogers, J. C. (1983). The study of human occupation. In G. Kielhofner (Ed.), Health through occupation: Theory and practice in occupational therapy (pp. 93-124). Philadelphia: F. A. Davis.

Rogers, J. C., \& Holm, M. B. (1992). Assistive rechnology device use in patients with rheumatic disease: $\mathrm{A}$ literature review. American Joumal of Occupational Therapy, 46, 120-127.

Smith, R. (1995). A client-centered model for equipment prescription (client's values and roles, effective use of adaptive equipment). Occupational Therapy in Health Care, 9(4), 39-50.

Spuhler, J. N. (1965). The evolution of man's capacity for culture. Derroit, MI: Wayne State University Press.

Technology-Related Assistance for Individuals With Disabilities Act. (1988). Pub. L. 100-407, 29 U.S.C. $\$ 2202$.

Tobias, P. V. (1966). The brain behind the hands. African Journal of Occupational Therapy, 1(16), 4-9.

Washburn, S. L. (1960). Tools and human evolution. Scientific American, 203(3), 1-15.

Wlodkowski, R., \& Ginsberg, M. B. (1995). Diversity and motivation: Culturally responsive teaching. San Francisco: Jossey-Bass.

Zemke, R., \& Horger, M. M. (1995). Hands: Tools for crafuing human adaptation. In C. Royeen (Ed.), Hands on: Practical interventions for the hand (chapter 1). Bethesda, MD: American Occupational Therapy Association. 